\title{
III \\ The Disquieting Workings of the "Uncanny": A Creative Device for Architectural Representation
}

\section{Karel Deckers}

Karel Deckers is currently working as an architect in Brussels,

Belgium in his own practice and regularly contributes written articles for the Giornale dell'architettura. He is a researcher and design assistant, department of interior Architecture,

St Lucas, Ghent and Brussels, Belgium. He is currently conducting $\mathrm{PhD}$ research at the Chalmers University of Technology in Gothenburg, Sweden.
ABSTRACT Fear has become an everexpanding part of life in the West in the twenty-first century. The architectural "Uncanny" is to be related with a specific kind of fear - an existential anguish without object (as opposed to fear out of danger which is always connected to something or somebody). The research into the "Uncanny" addresses a slightly disquieting, invisible, and often-forgotten component located between architectural praxis and theory, revealing a creative device in architectural design. Onheimelijk or "Uncanny" serves as a "positive" counterweight to traditional values in architecture (light, sight, visibility, and so on): it functions as a creative engine

Reprints available directly from the publishers

Photocopying permitted by license only (C) Berg 2010 Printed in the UK 
to generate meaning in architectural representation and architectural education. The current "culture of fear" calls for a better understanding and confrontation of imminent threats: this culture does not intimidate, but stimulates growth of human creativity through architecture. "Uncanny" facilitates an intentional understanding exploring grotesque possibilities in architecture and highlights an affective side to architecture. The transdisciplinary research examines how "Uncanny" contributes to experiments in architectural representation of diverse nature (e.g. written, drawn). By doing so, we implicitly take architecture away from certain conventions regarding (re)presentation.

KEYWORDS: Uncanny/Unheimlich, fear, interior architecture, architectural representation, research by design, plot

\section{Introduction}

Wandering and looking back at the accomplishments of the "Uncanny" throughout the centuries, one is struck by the omnipresence of the "Uncanny" in time and space. The "Uncanny" is embedded in the philosophical horizon of "Sein zum Tode," as professed in Heidegger's writings (Heidegger 1927). The sudden realization of mortality "condemns" humans to creativity: fear of nothingness makes humans decide - almost naturally - produce artifacts. In this article I hope to give a small, but significant, contribution to an expanding theory of the "Uncanny." I will try to shed a light on the discrete relation between various issues. The first part is a more "theoretical" inside view into the general cultural workings of the "Uncanny" with its creative, representational, narrative, and critical qualities in the second part.

Arguably, the origin of the fear in architecture or the architectural "Uncanny" can be found in the - often belligerent - interplay between the architectural interior (material space) and imagined interior (mental space). Both are within close reach and therefore probably most appropriate for a quest into the "Uncanny." In my opinion, the imagined interior itself does not have to be materialized per se into any architectural artifact in order to be considered "Uncanny." The graphical Carceri series by Piranesi (Ficacci 2000) in this respect is exemplary.

It is the childlike wonder that triggers the Sublime and combines architectural interior and interiority in an "Uncanny" union: it is a moment whereby humans touch upon precognitive and prereflective issues. Wonder instigates a qualitative and intentional view upon reality open to curiosity and learning. The moment of wonder submerges humans into existence itself, into one's own "facticity," 
Das Dasein (Heidegger 1927) or being-thrown-in-the-world, a prereflective state of being.

Closely related to wonder and curiosity is uncertainty and doubt. This mental attribute is partly responsible for the emergence of many artworks in history: writers, poets, visual artists, and scientists shaped and transformed doubt into art or science. Their artistic expression not only provokes, but also provides intellectual and emotional solace for both artist and audience. The architectural "Uncanny" can be shaped through written means (for instance, by authors and readers), drawn means (for instance, by interior architects and users of architectural artifacts), musical means (for instance, by musicians and their audience), or verbal means.

Works of art often portray ambiguous situations or persons leaving a feeling of awe or unheimlichkeit. For instance, certain types of graphical representation, historically instilled by the likes of Francisco Goya (Los Caprichos, 1797), Frans Masereel (Mon livre d'heures, 1919), Henry Füseli (The Nightmare, 1781), Caspar Friedrich (Wanderer above the Sea of Fog, 1818), and Giorgio Di Chirico (L'enigma di una giornata, 1914), and Carlo Carrà (II figlio del costruttore, 1917-21) with pittura metafysica, make the relation between fear and art apparent. Literary representations or narratives such as Das Schloss by Kafka (1988[1926]), Rise and Fall of the House of Usher (1990[1839]) by Edgar Allen Poe, and Malpertuis (1998[1943]) by Jean Ray are fine examples of the written and imaginary negotiation between architectural interiors and fearful spaces. Musical representations such as Joy Division with the album Closer (1980) sound unheimlich. A mix of spleen-filled lyrics, the choice of instruments, the specific structure of songs, the particular rhythm section, and the sleeve artwork stir the audience's imagination and make listening to their music a disquieting event. Another example is found in the music of Camille Saint-Saëns's Danse Macabre (1875). All these types of representation illustrate the workings of the "Uncanny": torment is made into art, and art is made into torment.

The research concerning the architectural "Uncanny" as a creative device for representation is framed by the science of philosophy, more specifically, the theory of phenomenology developed by Heidegger in his remarkable book Sein und Zeit (Heidegger 1927). His theory provides strong shoulders to support my research into the "Uncanny," as it professes a fundamentally inclusive approach towards reality. It opposes the stubborn Cartesian duality in (scientific) thinking. This duality arguably led to a positivist conception of reality, misanthropy, and absence of wonder. The phenomenological approach, however, is subject based: it emphasizes a vital ability to "return" to the phenomena as such. Central in phenomenology is the notion of "care" for things and beings (referred to by Heidegger as die Sorge) that safeguards specificity and qualities, against positivist tendencies. 
I believe phenomenology offers an opportunity to take interior architecture away from representational conventions. It also offers a more solid foundation in research to the notion of interiority, instigated by the imagination. One can argue that interiors and interiority are fundamentally dealing with the mental and physical inside of things, venturing beyond the obvious categories of numbers and data. This article focuses on the issue that the "Uncanny" is able to establish and re-create qualities related to interior space through the imagination of both audience and author.

The leading inquiry of our research is to find out how "Uncanny" contributes to a wide range of experiments in architectural representation (e.g. written, drawn). To do this I have chosen seven key figures with diverse backgrounds (Burke, Freud, Husserl, Heidegger, Norberg-Schulz, Bollnow, and Vidler). All of them are or were - consciously or unconsciously - involved in the activating potentialities of the phenomena of unheimlichkeit in their respective disciplines. We have chosen these figures as they represent different schools of thought, eras of thinking, and diversity in method building. The philosophical character of their work is a common ground.

What exactly is the historical and philosophical background of the "Uncanny"? In order to understand this philosophical character, we should start by looking at some key historical figures and moments. The "Uncanny" is undoubtedly rooted in the tradition of Romanticism. The division between the Sublime and the Beautiful goes back to the writings of Edmund Burke (1729-97) in A Philosophical Enquiry into the Origin of Our Ideas of the Sublime and the Beautiful (Burke 1909-14). Objects of art or forces of nature, for instance the depth of an abyss, the roaring sound of thunder, and the endless misty landscapes, make us wonder about a deeper reality that transcends us. Through these sensations we reach out to the Sublime and the Beautiful. While the Beautiful is principally linked to simple pleasures and joys, the Sublime is connected to a strong sensation of pain and terror. The Sublime thus becomes a source of fear and threat. But, it is necessary to keep a distance from these primordial fears. By detaching ourselves from them, we can experience something like "delight." The Sublime has links to many disciplines. Our research by design does not aim for an aesthetical response to Romanticism, nor are we making a historical study on contemporary phenomena related to Romanticism. It is more about gaining an understanding of where the "Uncanny" comes from and how it can be attributed to the field of architecture today.

The term "Uncanny" was introduced to science by Sigmund Freud (1856-1939): his writings on the phenomenon of the "Uncanny" contributed to the development of psychoanalysis as a discipline. By means of empathy, metaphors, stories, and dialogues, he argued that the human psyche contains fundamentally unconscious layers of information. These layers are repressed out of fear, frustration, and anger. It can be argued that his findings did install uncertainty 
and a fundamental distrust upon the lucid judgment of the human rationale: in this respect, the "Uncanny" is just one of his many arguments. In Das Unheimliche Freud (2006[1919]) starts fathoming the etymological meaning of the word "Uncanny" in many languages.

In German, the noun Heimlichkeit (homeliness) bears a double meaning: it means not only something familiar/homely/recognizable, but also something concealed. The opposite, Un-heimlichkeit ("Uncanny") also bears a double meaning: something that is at first hand not at home, unfamiliar, and unrecognizable. But, the second meaning (to disclose, to unveil something) makes the understanding of the Un-heimlichkeit suddenly complex and intriguing. Conclusively, at first sight, the "Uncanny" is an instance that is familiar, though immediately afterwards it is revealed as something strangely and disquietingly familiar. Therefore somebody encountering an "Uncanny" experience is left feeling somewhat bewildered, perplexed, and uncomfortably strange.

One could argue that the architectural "Uncanny" is to be found in philosophical works of Martin Heidegger (1889-1979) and his teacher Edmund Husserl (1859-1938). Husserl first founded the theory of phenomenology and intentionality (Husserl 1997[1907]). His pupil, Heidegger, elaborated his work further and developed the intentional notion of "Sein zum Tode" (Heidegger 1927) or "beingtowards-death": our existence has a meaning and direction because of the realization of mortality. This notion of "being-towards-death" is complementary to our "being-in-the-world," in which one is continuously "being thrown in a world-of-possibilities" (Heidegger 1927). Both notions, "being-towards-death" and "being-in-the-world," hold the key to understanding the very essence of architectural creativity and our natural care for reality and "things." Creativity is limited and guided by mortality of things and passing of time. In other words, a creative act is intrinsically connected to our awareness of mortality, thereby linking architecture and fear in a paradoxical and complex union.

The architectural theoretician Christian Norberg-Schulz (19262000) is clearly influenced by the phenomenology of Heidegger and Husserl. In his Architecture: Presence, Language, Place (NorbergSchulz 2000) he tells us that our "being-in-the-world," or das "Dasein" always encompasses four essential elements: the sky and earth, the presence of mortals and gods. These four elements, the so-called "quadrature" or fourfold of "things," are tied together and always surface simultaneously. In other words, every architectonic creation invariably is united and fulfilled by the synchronous presence of these four elements. This "quadrature" refers to a spatial component of his phenomenology.

Norberg-Schulz also developed a phenomenology related with time, consistent with the theory of intentionality and phenomenology of Husserl and Heidegger. According to this time-based phenomenology, there are basically three kinds of perception related 


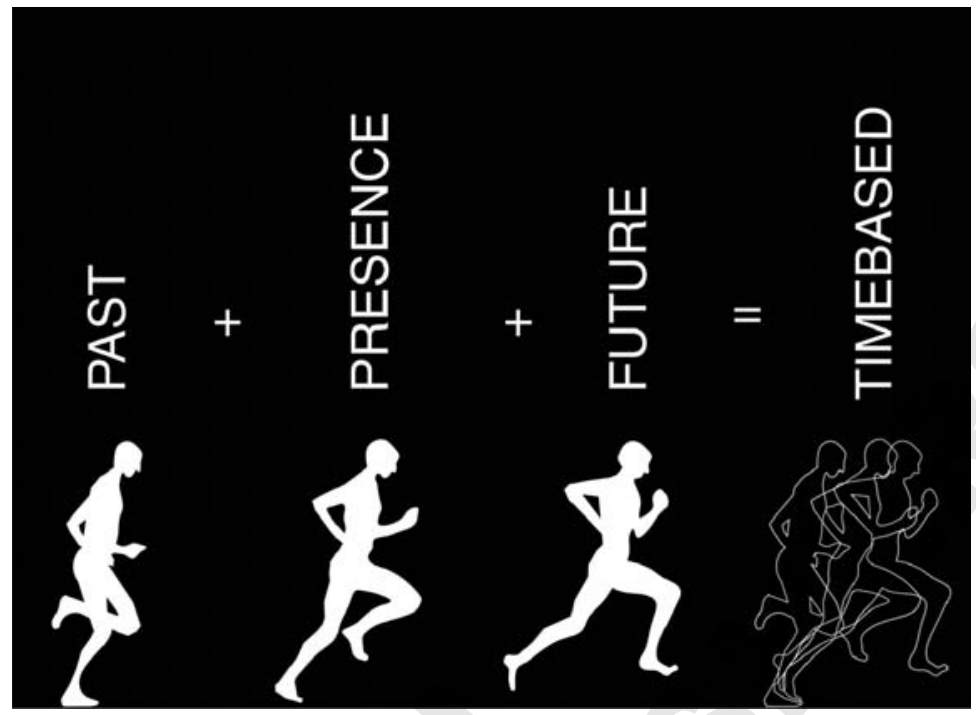

Figure 1

Threefold phenomenology of time developed by Christian Norberg-Schulz (based on Husser and Heidegger). Any act of thinking is the simultaneous assemblage of past (memory), present (identification), and future (orientation).

to time. First, there is our perception of the past, all the things we knew previously (memory). Secondly, our perception of the present: we tend to consider somebody or something AS somebody/ something (identification). Finally, our perception of future: what we do (not) expect (orientation/anticipation). Our perception of reality is always synchronically guided by these three perceptions of time: we are intentionally and simultaneously memorizing (past), orientating (future), and identifying (present) (see Figure 1). I will come back to this threefold notion of time later in the article as it is important for understanding the objectives of the "Uncanny."

By studying the "Uncanny" in interiors, one also relates inevitably to the study Mensch und Raum (1963) made by O. Bollnow (1903-91), philosopher and pedagogue. For example, this study describes the igniting imagination of a child facing darkness in which sensible perception of space ceases to exist. As seen from a child's perspective, the world of materials and forms seems to be everchanging, magnified, stretched, and magic. A child that is left in the dark almost instantly designs a new and ever-changing universe out of the sublime mixture of wonder and fear, regardless of any conventions.

Natural and subliminal landscapes with dense forests, thick mists, and snow are analyzed as if they were interiors. In doing so, interior architecture is brought into a strange alliance with the experience of "Uncanny" natural environments. The "Uncanny" aims at understanding the primary forces (the Sublime in relation to terror, 
and wonder related to uncertainty) as extremely creative design features.

Architectural historian and theoretician Anthony Vidler relates the "Uncanny" with architectural issues in his influential book The Architectural Uncanny (Vidler 1992). It is written from a historical point of view and describes several cases the "Uncanny" as a "discomforting" cultural phenomenon or tendency that manifests itself through arts, literature, architecture, psychology by phobias, and archaeology. In the eighteenth-century, archaeologists excavated Herculean petrified corpses: the corpses, being buried alive, set a terrific example whereby humanity is able to see and anticipate inevitable death. This example triggered eighteenth-century authors to write similar horror stories. Reading Vidler's book one becomes acquainted with how the "Uncanny" surfaces as a broad cultural theme throughout centuries. In my research, the "architectural Uncanny" acts as a sort of an umbrella term for many issues related to architecture and the "Uncanny."

\section{Architectural Theory of the "Uncanny"}

When we accept that the "Uncanny" is related to pre-reflective and phenomenological issues that are partially instigated by the aforementioned influential figures, I can then try to develop an architectural theory out of it. I have discovered throughout my research several creative characteristics emerging from the architectural "Uncanny" - the theory of the architectural "Uncanny" is both inclusive, transdisciplinary, and sinister, and indulges in risks.

Firstly, the "Uncanny" is "inclusive" (Van Berkel 1998) by nature: it unveils and veils/orders and disorders/unfamiliarizes and familiarizes. The "Uncanny" bears in itself two opposites (it alienates and reveals at the same time). This contradiction within one term can be considered as something "inclusive." The "Uncanny" does not want to exclude complexity nor does it exclusively want to simplify: it includes both in one concept. It stimulates joy and decay at the same time. Order and disorder are part of the same constellation. "Uncanny" does not impel one to the choosing of sides but rather tends to precede every imaginable division and acts within a pre-reflective setting of things. The "Uncanny" also encompasses time and space in one gesture: it follows the logic of Heidegger's phenomenology with its subject-driven, inclusive, and time-based perception of reality. Any act of thinking is assembled simultaneously in past, present, and future.

"Uncanny" also tends to transgress scientific disciplines. Throughout my research, I gradually realized that not only the physical building or space is a primal source of fear. Our personal background with specific education, memory, and so on should be taken into consideration as well. The psychological component of the "Uncanny" matters just as much as it deals with unconscious and tacit issues. The latent and repressed nature of our unconsciousness 
continuously seeks compensation by resurfacing unexpectedly and erratically.

On a philosophical level, the aforementioned key figures such as Heidegger and Husserl tell us that humans are always confronted with (passing of) time. Next to this, one has a natural care for things and the "other." In many media outside the architectural field The "Uncanny" represents itself globally: media companies cover contemporary stories of horror and crisis situations as if it is daily bread.

The "Uncanny" can be considered as sinister and imaginative: the "Uncanny" reveals sinister and hidden qualities behind the superficial curtain called architecture. These subtle qualities are equivalent to traditional and maybe obvious spatial values like light/sight/air. They make us aware of the important role of architecture as a discipline that is able to reveal and hide at the same time. The architectural "Uncanny" is about unraveling a multitude of layers in which architecture is hidden and can be excavated. Many values related to the architectural experience depend on the immaterial, invisible, intangible, and often "erratic," thus unpredictable, aspects. Another sinister aspect is the mortality of all things and beings: architecture is probably not immortal but needs the horizon of mortality in order to exist. This is very important in order to understand the "Uncanny" in architecture: the architectural artifact may outlive several generations, but finally we are all are limited to our own ending.

The "Uncanny" provokes by causing people to "indulge" in crisis situations/calamities. This provocative feature of The "Uncanny" returns on many levels. In architectural practice, a deadline is an artificial and self-induced moment of crisis that finally nourishes an eagerness to come up with a sharp design. The "Uncanny" is also an intentional attitude towards risks. To put it polemically, to avoid a design problem is to avoid the possibility of generating architecture. The "Uncanny" is about willfully seeking out risks and crisis/danger/ pain/fear. The architectural design of the "Uncanny" flourishes in the context of catastrophe and imminent danger. The "Uncanny" can also be considered as an operational design issue: one can argue that a design is richer when it embraces spatial issues along with movement and time. This willful and deliberate search for complexity is essential to understand the architectural "Uncanny."

\section{Objectives of the "Uncanny"}

We have seen some of the background and characteristics, but what are the real objectives of the "Uncanny"?

The "Uncanny" affects our notion of time as it emerges before, during, and after a specific architectural experience. The "Uncanny" can be experienced by physically moving through a building, space, or situation. We are hereby guided by our imagination by synchronically incorporating three kinds of perception related to time. First, our perception of the past: all the things we knew previously (memory). Secondly, our perception of the present: we tend to consider 
something as something (identification). Finally, our perception of future: what we do (not) expect (orientation/anticipation). Thanks to the theory of intentionality (Husserl 1997[1907]) and the further elaboration by Norberg-Schulz (2000) we know that our perception of reality is always guided by three elements: we are intentionally and simultaneously memorizing (past), orientating (future), and identifying (present), thus intentionally inciting imagination while experiencing the "Uncanny."

The "Uncanny" also tends to increase empathy, participation, affective, and emotional aspects in architecture. It is therefore addressing a wider, non-specialized audience. As stated above, through a specific representation of the architectural "Uncanny", we can experience and obtain an increased understanding of affective and emotional aspects in architecture. This dimension makes us more involved and affectionately connected to the work of art/artifact. In this respect, we can refer to the "Stendhal syndrome," whereby one enters in an emotional turmoil after having been exposed to a multitude of beautiful artworks. Most paradoxically, we are also becoming empathetically connected to something or somebody who is potentially threatening us! This phenomenon is somewhat reminiscent of the Stockholm syndrome: a paradoxical and psychological phenomenon whereby empathy and even sympathy is induced by hostages to (the cause of the) hostage takers.

The "Uncanny" also facilitates understanding of the psychological aspects related to fear and space. The "Uncanny" contributes a meaning to space that goes beyond the familiar and immediately recognizable: we are both simultaneously alienated and drawn to its workings. This contradictory process is predictable in itself, but at the same time disquieting as the outcome is always uncertain. This continuous process of taking distance and approximating (and back again) makes us - as an audience (visiting or reading) - more involved and affectionately connected to the space or object of art. For instance, imagine yourself walking along a cliff. As a free being, one can be suddenly confronted by thoughts of losing control. There is a genuine anguish that emerges if one has the freedom to throw oneself down to an imminent death. One could say that our confidence to confront space is continuously under siege through an inbuilt and existential uncertainty. Onheimelijk is very much about adopting an authentic and intentional attitude, accepting ever-changing realities, even if they are disturbing kinds of realities.

Finally, the "Uncanny" manifests itself through a specific architectural representation. The works of art by somebody like Piranesi are exemplary to understand the "Uncanny" in architectural representation: his study of the Carceri (Ficacci 2000) were, in a way, predicting troubled times. Also, the findings of Bernard Tschumi (1994[1979]) in his The Manhattan Transcripts in this respect are truly exceptional: this work is an unfinished symphony into the representation of the architectural "Uncanny." Its importance lies in the implementation 
of collage and film techniques combined with traditional architectural techniques (diagram, plan, and isometric). The Manhattan Transcripts with experiments of combining movement, action, time, and architectural representation gives a significant indication of how this sublime mixture of space and time could be represented. The writings and images of Tschumi explore radical experiments in architectural representation and seek the establishment of new meaning in architecture. Unfortunately, the book has not been implemented more broadly into architectural practice or education.

\section{Merging of Time and Space in Comics and Architecture}

By combining all the objectives of the "Uncanny" - the synchronic threefold notion of time, the increased empathy with non-specialized audiences, and a better understanding of psychological effects of fear and space - we can then understand that the "Uncanny" has something to do with representation inducing fear and sympathy simultaneously in the field of architecture. This usually happens when time and space starts merging into a sublime and inclusive union. We need, therefore, to understand better the issue of the passing of time from an "Uncanny" point of view (maybe even more than we need to understand issues related to space). Time is preferential to all spatial issues as our notion of time is intertwined with our own realization of mortality. Without the notion of time, there would neither be architectural experience nor representation: everything would be frozen.

In conventional architectural representation, there are already a lot of techniques related to merging of time and space. A cross-section of an interior, for example, is an artificial and "mental" construct combining time and space. The movement (time) of different users on different floor levels can thus be simultaneously verified optically in one drawing. This possibility of simultaneously viewing separate interior spaces does not exist in reality: it only exists in the drawing! An interesting figure who started challenging the impossibility of simultaneously viewing separate interiors is the artist Gordon MattaClark (1943-78). His radical "cutting techniques" and adaptations of existing interiors relate in a strong way to the "Uncanny," opening up inclusive possibilities. The potential audience can be omnipresent in many places at the same time, opening up a panoptical device encompassing past, present, and future.

Arguably, sequential graphic art like comics is a great way to discover the architectural experience with its merge of time and space. The narrative qualities of comics are an excellent way to discover representation of the "Uncanny." Addressing this issue, it can be very helpful to read work of the comic author Scott McCloud (1994). He states that a comic's panels offers an irregular sequence of unconnected moments fracturing both time and space. But, by connecting the panels in a conventional sequence (from left to right) something 

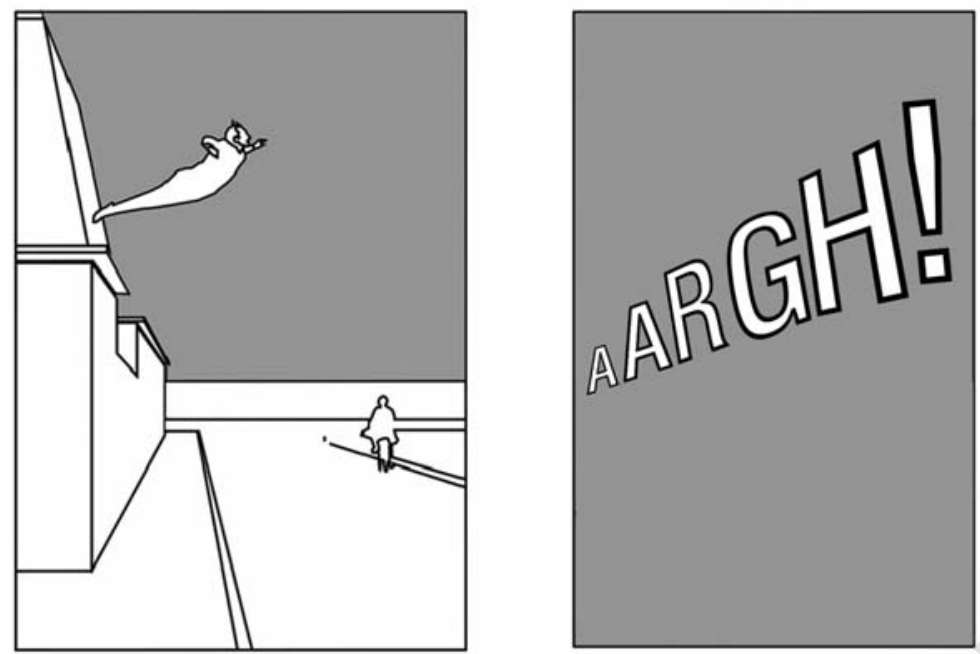

Figure 2

"Closure": the reader is invited to willfully and mentally connect the "gap" between panels in a continuous and unified reality.

interesting occurs. Through the notion of "closure" (Figure 2), the reader is invited to intentionally and mentally connect the "gaps" between panels in a continuous and unified reality. The arrangement of a comic's page or even one panel is, in fact, a condensed form of time and space put in a narrative sequence: it is a temporal map. The images and the language are combined in such a way that the plot encompasses movement, time, and space in one panel, in one page, in one comic.

In architectural experience, we encounter also a similar phenomenon: "closure" occurs when the "audience" or visitor passes through - intentionally designed - contrasting spaces. This instance of intentional disorientation facilitates the growth of imagination and possibly dread to any kind of audience. I would like to start by giving a famous example: the Opera by Tony Garnier in Paris (Figure 3). The architectural movement through the building is intentionally guided by a staccato rhythm of perspective transformations. Garnier's opera building seems not to lead to one absolute plot or narrative climax: the architectural experience can be read as a succession of many subplots. The author (the architect) is leading the audience into a seemingly endless cloud of architectural wonder. What the (narrative) plot of the building ultimately deals with is much less straightforward.

One could argue that the architectural experience of sequential spaces in this opera building is "fluid," but not per se "linear"; in other words, the architect does not necessarily design towards a plot in a "linear" fashion. From a visitor's point of view, an architectural experience of space is probably of a nonlinear kind as the sequence of spaces can be easily "read" reversely from the end to beginning 


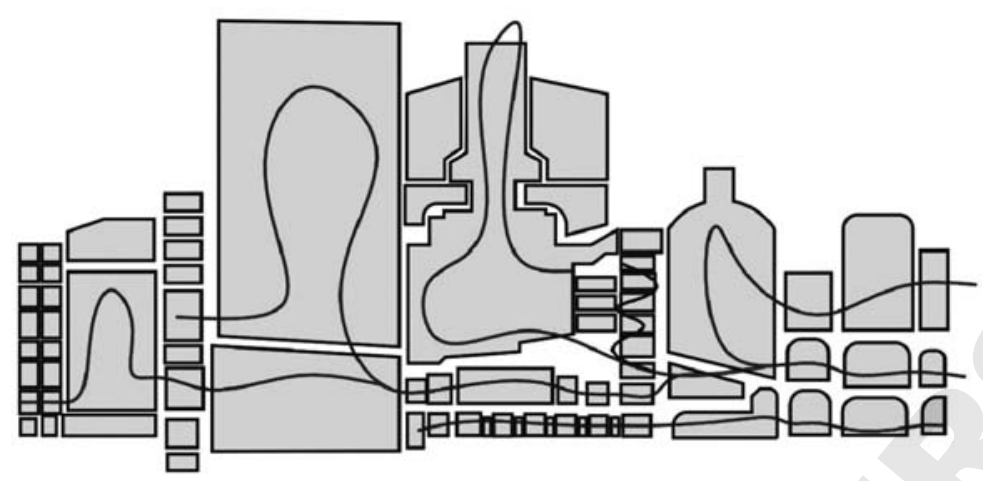

Figure 3

The architectural experience can be read as a succession of many subplots.

or even in between the end and beginning. Still, one can argue that the plot (and subplots) or narrative has been programmed before: it has been "preset" and instilled by its author, the architect. This brings us to an interesting issue: the tension between a preset narrative in architecture and the will to escape from this narrative by the author and/or the audience.

How does the architectural "Uncanny" relate to the problem of a preset narrative or plot? Malin Zimm (2005) asks the poignant question, should we lose the plot or not? Should an architectural narrative be preset or not? One option is "to lose the plot" in architecture. We can choose to do this for a particular and critical reason. Since Modernity, it is generally regarded that plots can intentionally or unintentionally act as agents of power. A plot clouds our imagination in a negative way as it paralyzes our critical ability. So logically, we would choose to lose the plot, because of a natural interest in "maintaining our critical abilities" at all times. Alternatively, one can also consider a plot as a narrative method in order to induce a pleasant and uninterrupted whole leading up to a singular climax. So, there is a sort of duality - or dilemma, if you prefer - to choose sides between having a plot or not.

We argue that the "Uncanny" with its intentional qualities is most likely able to absorb the duality between having a plot or not: the "Uncanny" can contain both at the same time as it does not consider the principal differences between the two. The concept of the "Uncanny" does serve as a critical vehicle against fragmentation. It criticizes the mental slavery and addiction to plots, but paradoxically does not exclude that plots will provide answers. The power of "Uncanny" in architecture resides in its inclusive working: the appropriation of space and time by an intentional audience/intentional user constantly transforms bits and pieces into comprehensible wholes. Logically, architectural "Uncanny" is an ally in the resistance against losing consciousness of invisible and intangible aspects "behind reality." It thereby resists firmly against tendencies to fragment 
reality and destroy magic and wonder. This is a legitimate act of self-defense as "Uncanny" originates in magic and wonder.

\section{Conclusion}

In a disenchanted world dominated by numbers and data, the "Uncanny" is born out of wonder and profoundly affects our "beingtowards-death." By crossbreeding several disciplines, Unheimlich transgresses the verticality imposed by a specific kind of positivist thinking. The study on the "Uncanny" focuses beyond the here and now by consciously incorporating the horizons of "tradition" (past) and anticipation (future). By doing so, a synchronic perception of reality emerges. Through that specific notion of temporality, we can approximate the workings of "Uncanny."

The theory of architectural "Uncanny" summarizes the activating potentialities in architectural representation, practice, and science. After acknowledging the ambiguous, sinister, and hazardous nature of the "Uncanny" (danger, mortality, decay, and ultimately death), the phenomenon of the "Uncanny" reveals a "world-of-possibilities."' Passing of time, empathy, subconscious desires, specific representation, and space melt inclusively into one powerful concept in order to create and understand meaning in architecture.

Through the "Uncanny," the (preset) architectural narrative (i.e. plot) is critically questioned: the architectural experience is guided both by author and by potential reader. Through the notion of "closure," we have found a powerful way to induce involvement and participation for both parties. This notion of "closure" has the capacity to introduce the experience of time in architectural representation.

The architectural "Uncanny" is an attitude towards simultaneously bridging the gap between the world of the reader and that of the author, user and architect, theory and practice, imagination and representation, time and space. In other words, as a theory and a practice, the architectural "Uncanny" has the ability and inherent duty to become a creative device for architectural representation. In return, the produced results inform the theory of the architectural "Uncanny" and vice versa.

\section{References}

Bollnow, Otto F. 1963. Mensch und Raum. Stuttgart: Kolhammer. Burke, E. 1909-14. A Philosophical Enquiry into the Origin of Our Ideas of the Sublime and the Beautiful, The Harvard Classics. New York: P. F. Collier \& Son.

Ficacci, L. 2000. Piranesi: The Etchings. Rome: Benedikt Taschen.

Freud, S. 2006[1919]. The Uncanny. London: Penguin Books.

Heidegger, M. 1927. Sein und Zeit. Leuven: Kritak.

Husserl, E. 1997[1907].Thing and Space: Lectures of 1907. Leuven: Kritak.

Kafka, F. 1988[1926]. Das Schloss. Amsterdam: Querido. 
McCloud, S. 1994. Understanding Comics: An Invisible Art. New York: Harper.

Norberg-Schulz, C. 2000. Architecture: Presence, Language, Place. Milan: Skira.

Poe, E. A. 1990[1839]. Rise and Fall of the House Usher. Amsterdam: Loeb.

Ray, J. 1998[1943]. Malpertuis. London : Atlas Press.

Tschumi, B. 1994[1979]. The Manhattan Transcripts. London: Academy Editions.

Van Berkel, B. 1998. Move. Rotterdam: Goose Press.

Vidler, A. 1992. The Architectural Uncanny: Essays in the Modern Unhomely. Cambridge, MA: The MIT Press.

Zimm, M. 2005. Losing the Plot. Stockholm: Axl Books. 